Check for updates

Cite this: Chem. Sci., 2019, 10, 7082

๑ All publication charges for this article have been paid for by the Royal Society of Chemistry

Received 27th March 2019

Accepted 7th June 2019

DOI: $10.1039 / c 9 s c 01513 b$

rsc.li/chemical-science

\section{Hypercoordinate iodine for catalytic asymmetric diamination of styrene: insights into the mechanism, role of solvent, and stereoinduction $\dagger$}

\author{
A. Sreenithya, (D) ${ }^{a}$ Christopher M. Hadad (D) ${ }^{b}$ and Raghavan B. Sunoj (D) *a
}

Hypercoordinate iodine has evolved as an impressive class of catalysts for various organic transformations. Extension of this idea to asymmetric applications, such as in the asymmetric difunctionalization of styrene or its derivatives, constitutes an important reaction. In this study, the mechanism and origin of stereoinduction in styrene diamination, with a sulfonimide $\left(\mathrm{HNMs}_{2}\right)$ as the diaminating agent and iodoresorcinol $\left(\left((\mathrm{iPr})_{2} \mathrm{~N}(\mathrm{CO})-\mathrm{CH}(\mathrm{Me})-\mathrm{O}\right)_{2} \mathrm{Ar}-\mathrm{l}\right)$ based chiral hypercoordinate iodine as the catalyst, are investigated using density functional theory calculations. The energetically preferred catalytic pathway has been found to involve, among other steps, two very important mechanistic events: (a) the formation of a catalyst-substrate complex by the action of styrene on the catalyst $\operatorname{Arl}\left(\mathrm{NMs}_{2}\right)_{2}$, resulting in the displacement of one of the imidates $\left(\mathrm{NMs}_{2}{ }^{-}\right.$); and (b) a rebound of the departed imidate on the iodinebound styrene to form an iodonium ion intermediate with a $\mathrm{N}-\mathrm{C}$ bond. Explicit interaction of the imidate ion with hexafluoroisopropanol (HFIP), used as a solvent additive, lowers the barrier for the formation of the iodonium ion. The $P$ helical fold of the chiral arms of the iodoresorcinol catalyst is found to offer a chiral environment for the reactants. Coordination of the iodine catalyst to the styrene double bond is found to make the benzylic carbon more electrophilic and hence makes it the preferred site for the nucleophilic addition. In the chiral environment of the catalyst, an enhanced polarization of the styrene double bond is noticed when the double bond coordinates through the si prochiral face than the re face. Nucleophilic addition on the re face of the catalyst-substrate complex is associated with a lower activation barrier leading to the experimentally observed $S$ enantiomeric product. The stereoselective model developed in this study can be employed to related asymmetric styrene difunctionalizations using similar hypercoordinate iodine catalysts.

\section{Introduction}

Vicinal diamines are important structural elements in pharmaceuticals, natural products, and organo- as well as transition metal catalysts. ${ }^{1}$ Hence, efficient methods for the synthesis of diamines are of great interest. ${ }^{2}$ Palladium- and copper-catalyzed asymmetric diamination of alkenes involving intramolecular $\mathrm{C}-\mathrm{N}$ bond formation is the most frequently found catalytic diamination reaction. ${ }^{3}$ Among the metal-free approaches, hypercoordinate iodine mediated diamination of alkenes has received considerable attention in recent years. ${ }^{4}$

Hypercoordinate iodine mediated methods have found widespread acceptance owing to their utility in a diverse set of

\footnotetext{
${ }^{a}$ Department of Chemistry, Indian Institute of Technology Bombay, Powai, Mumbai 400076, India. E-mail: sunoj@chem.iitb.ac.in

${ }^{b}$ Department of Chemistry and Biochemistry, The Ohio State University, 100 West $18^{\text {th }}$ Avenue, Columbus, Ohio 43210, USA

$\dagger$ Electronic supplementary information (ESI) available: Cartesian coordinates of all stationary points and other relevant information is provided. See DOI: 10.1039/c9sc01513b
}

reactions under milder and environmentally benign conditions. ${ }^{5}$ An excellent strategy for diamination of styrene derivatives in the presence of a stoichiometric amount of phenyliodine(III) diacetate (PIDA) with two equivalents of sulfonimide $\mathrm{HNMs}_{2}$ as the aminating agent (Scheme 1a) was recently reported. ${ }^{6}$ This method offers wide substrate scope and functional group tolerance. ${ }^{7}$ Replacing PIDA with chiral iodoresorcinol derivatives could provide asymmetric diamination. ${ }^{6}$ In a recent catalytic version of this reaction, catalytically active chiral hypercoordinate iodine species was generated in situ from the corresponding $\mathrm{Ar}-\mathrm{I}(\mathbf{4})$ and $\mathrm{HNMs}_{2}$ in the presence of two equivalents of meta-chloroperbenzoic acid ( $m \mathrm{CPBA})$ as an oxidizing agent (Scheme 1b). ${ }^{8}$

Difunctionalization of alkenes using hypercoordinate iodine(III) has found interesting applications in the synthesis of complex target molecules. ${ }^{9}$ In particular, iodoresorcinol based catalysts derived from the corresponding Ar-I (similar to 4) have been recently used for stereoselective difunctionalization of various styrenes, in which the $S$ stereogenic center at the benzylic position was formed in the product. ${ }^{9 a-c}$ Different chiral iodoresorcinol derivatives differ in terms of the substituents 

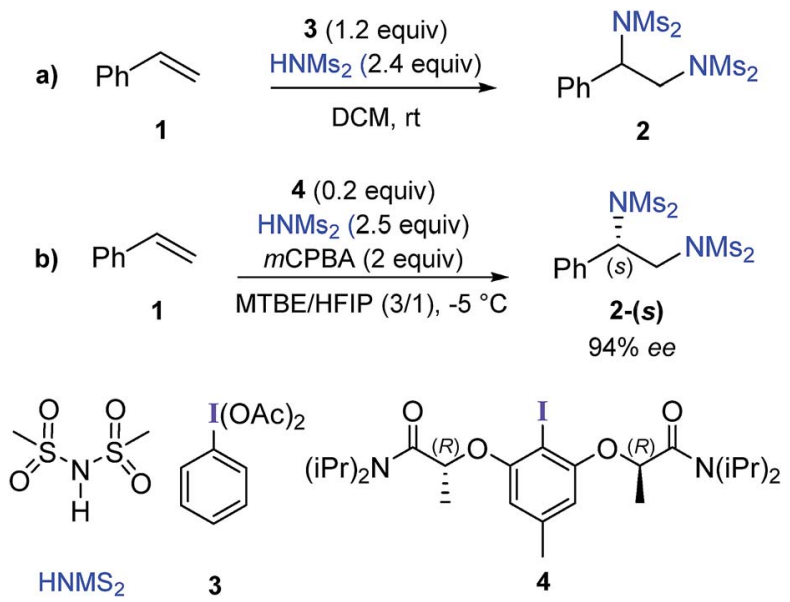

Scheme 1 (a) Stoichiometric and (b) catalytic diamination of styrene using hypercoordinate iodine.

attached to the carbonyl $\left(-\mathrm{N}\left(\mathrm{iPr}_{2}\right)\right.$ in the representative example 4) and $\mathrm{C}_{\alpha}$ (-Me in 4) positions of the chiral arms, while maintaining the $R$ configuration at the $\mathrm{C}_{\alpha}$ position. This observation indicates that the preferred prochiral face of styrene involved in all of these reactions is the same, such that the $(S)$-configured enantiomer of the product is generated. However, the origin of stereoinduction in these reactions is often interpreted using qualitative working hypotheses. ${ }^{10}$ In view of the impressive developments in asymmetric catalysis using hypercoordinate iodine, ${ }^{11}$ we probed the origin of stereoinduction ${ }^{12}$ in styrene diamination by using $\operatorname{DFT}\left(\mathrm{SMD}_{\text {(diethylether) }} / \mathrm{M} 06-2 \mathrm{X} / 6^{-}\right.$ $\left.31 \mathrm{G}^{* *}, \mathrm{SDD}(\mathrm{I})\right)$ computations.

\section{Computational methods}

All geometry optimizations were performed using the Gaussian09 suite of quantum chemical programs. ${ }^{13}$ The M06-2X density functional was chosen for geometry optimization which accounts for the potentially significant dispersion interactions in relatively larger molecules. ${ }^{14}$ The $6-31 G^{* *}$ basis set was chosen for all atoms, except for iodine. ${ }^{15}$ The Stuttgart-Dresden double-zeta valence basis set (SDD) with an effective core potential for 46 inner electrons was employed for iodine. ${ }^{\mathbf{1 6}}$ Solvent effects were incorporated using the universal SMD continuum solvation model developed by Truhlar and Cramer. ${ }^{17}$ The experimental conditions for the catalytic asymmetric reaction employed a solvent system consisting of a $3: 1$ mixture of methyl tert-butyl ether (MTBE) and hexafluoroisopropanol. Since the dielectric continuum field for $\operatorname{MTBE}(\varepsilon=4.5)$ is not available in Gaussian09, implicit solvation calculations for closely related diethyl ether $(\varepsilon=4.2)$ were employed. Hexafluoroisopropanol was explicitly included in several stationary points to evaluate specific interactions with the solute. All stationary points were verified by vibrational frequency analysis. Minima (reactants, products, and intermediates) were characterized by having zero imaginary vibrational frequencies, while transition states had only one imaginary frequency. Further verification of the transition states was done using intrinsic reaction coordinate (IRC) calculations in order to connect to the corresponding reactants and products. ${ }^{18}$ We wish to convey that locating various transition state geometries in hypercoordinate iodine catalyzed reactions could be challenging due to geometry convergence issues. Similar computational methods to those employed in this study have successfully been employed in recent studies of hypercoordinate iodine reactions. ${ }^{19}$

Topological analysis of the electron densities, within the Atoms In Molecule (AIM) framework, was carried out using AIM2000 software to identify the bond paths representing the weak inter-atomic interactions. ${ }^{20}$ Natural bond orbital (NBO) ${ }^{21}$ analysis of important stationary points was done to understand important electron delocalizations and charge distributions. To examine the origin of energy difference between the stereocontrolling transition states, the activation-strain model was employed. ${ }^{22}$ In this model, the activation barrier $\left(\Delta E^{\ddagger}\right)$ is considered as the sum of (a) destabilizing distortion energies $\left(\Delta E_{\mathrm{d}}^{*}\right)$ in the reactants while going from their ground state geometries to those in the transition states, and (b) stabilizing interaction energy between such deformed reactants $\left(\Delta E_{1}^{\ddagger}\right)$ in the TS geometry. This approach would help quantify the relative distortion and interaction energies between the stereocontrolling transition states.

The discussion is presented on the basis of the Gibbs free energies at $298 \mathrm{~K}$ and as obtained at the $\mathrm{SMD}_{\text {(diethylether) }} / \mathrm{M} 06$ $2 \mathrm{X} / 6-31 \mathrm{G}^{* *}, \mathrm{SDD}(\mathrm{I})$ level of theory. Gibbs free energies are corrected using Truhlar's quasi-harmonic approximation to address the issues arising due to the harmonic oscillator approximation for frequencies lower than $100 \mathrm{~cm}^{-1} \cdot{ }^{23}$ Gibbs free energies were also calculated using the quasi-rigid rotor harmonic oscillator (RRHO) approximation for the purpose of comparison, which is provided in the ESI. $\dagger^{24}$ The energies obtained at the $\mathrm{SMD}_{\text {(diethylether) }} / \mathrm{M} 06-2 \mathrm{X} / 6-31 \mathrm{G}^{* *}, \mathrm{SDD}(\mathrm{I})$ level of theory were refined using a larger basis set using the same functional to learn that the results were similar. Geometries were also optimized at the B3LYP-D3 level of theory. Energy refinements at the B3LYP-D3 level of theory using the geometries at the same level of theory were also carried out to check whether our results were consistent across different functionals. $^{25}$

\section{Results and discussion}

We have investigated all of the likely elementary mechanistic steps to develop an improved understanding of the key intermediates and transition states (TSs) involved in the diamination reaction, as shown in Scheme 2. An achiral hypercoordinate iodine species $\left(3^{\prime}\right)$ was considered first to develop some basic understanding about the key mechanistic features. The factors responsible for stereoinduction are then delineated by considering the chiral hypercoordinate iodine species that is derived from 4.

First, an achiral $\mathrm{PhI}\left(\mathrm{NMs}_{2}\right)_{2}\left(3^{\prime}\right)$ is employed as an active catalyst $[\mathbf{I}]^{\prime}$ to gather important mechanistic details (Scheme $2)^{26,27}$ The substrate styrene can displace one of the labile imidate $\left(\mathrm{NMs}_{2}{ }^{-}\right)$ligands to form a catalyst-substrate ion-pair complex, $\mathbf{C 1} .^{28}$ The natural bond orbital analysis (NBO) of C1 


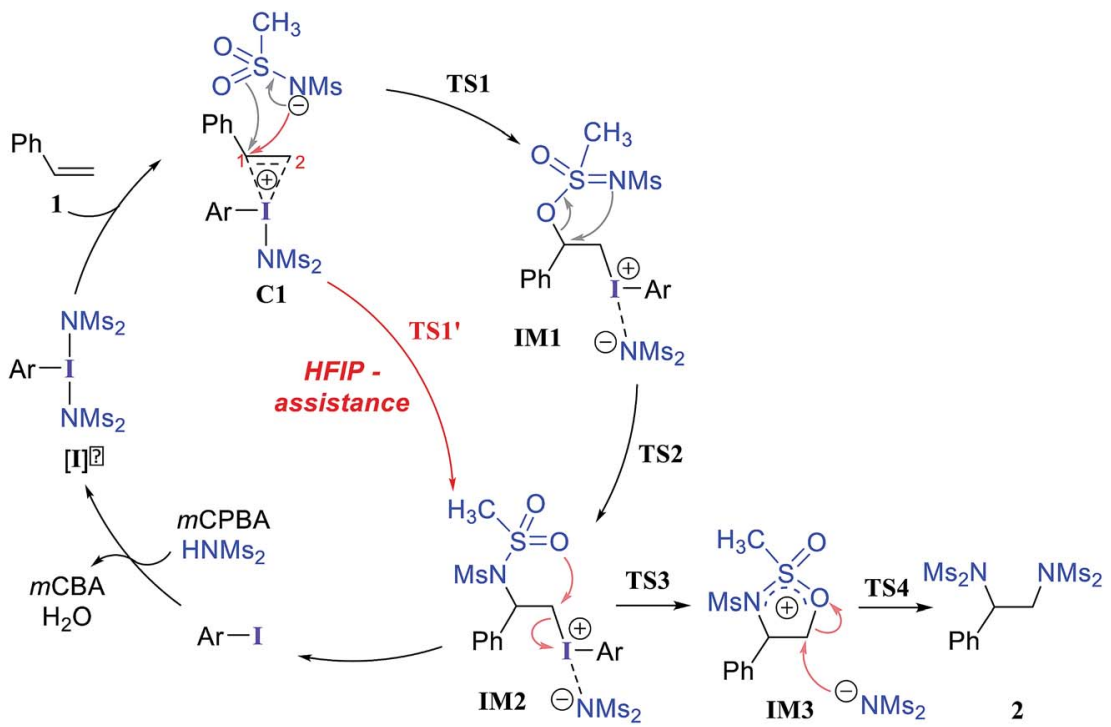

Scheme 2 Mechanism for catalytic vicinal diamination of styrene using hypercoordinate iodine.

revealed a prominent $\pi$ electron delocalization (45.1 $\mathrm{kcal} \mathrm{mol}^{-1}$ ) from the styrene double bond to the I(III)-N antibonding orbital. ${ }^{29}$ The coordination of the styrenyl double bond to the electrophilic I(III) center is found to induce a polarization such that the benzylic carbon $\mathrm{C}_{1}$ becomes relatively more positive (natural charges on $\mathrm{C}_{1}=-0.12$ and on $\mathrm{C}_{2}=$ -0.54 in $\mathbf{C 1}$ whereas that on an unbound free styrene is $\mathrm{C}_{2}=$ -0.43 and $\mathrm{C}_{1}=-0.25$ ), making the $\mathrm{C}_{1}$ benzylic carbon more prone to nucleophilic addition. The polarization of the styrene $\pi$ orbital in this catalyst-substrate complex is evident from a relatively higher $\pi$ orbital coefficient $(0.75)$ on the $\mathrm{C}_{2}$ carbon than on $\mathrm{C}_{1}(0.65)$, which was the same for a free styrene (orbital coefficient of 0.70 on both $\mathrm{C}_{1}$ and $\mathrm{C}_{2}$ ).

In the next step, we considered a rebound mechanism wherein the displaced sulfonamide anion adds to the polarized styrenyl double bond. Due to effective charge delocalization from nitrogen to oxygen in the imidate ion, the nucleophilic addition can occur either through the oxygen or through the nitrogen. The natural charges on the nitrogen $(-1.32)$ and the oxygen $(-1.04)$ of the imidate indicate that a nucleophilic addition through the nitrogen is more likely. However, attempts to locate a transition state for the nucleophilic addition through the nitrogen remained unsuccessful, and instead resulted in an addition through the oxygen (TS1)..$^{\mathbf{3 0 , 3 1}}$ The comparison of nucleophilicity indices of 0.61 and 0.08 , respectively, for the nitrogen and oxygen suggests that a nucleophilic addition through the softer sulfonyl oxygen is likely to be more preferred at the benzylic carbon of the iodine-bound styrene resulting in the iodonium ion intermediate $\mathbf{I M 1} .^{32}$ In the next step, a concerted intramolecular migration converts IM1 to IM2 via TS2 ${ }^{33}$ Formation of the second iodonium ion intermediate IM2 is exergonic by $\sim 16.0 \mathrm{kcal} \mathrm{mol}^{-1}$ (Fig. 1). An intramolecular nucleophilic addition by the sulfonyl oxygen at $\mathrm{C}_{2}$ can now provide a cyclic oxazolidine oxide intermediate, IM3. The barrier to this elementary step for the expulsion of $\mathrm{PhI}$ is
$11.4 \mathrm{kcal} \mathrm{mol}{ }^{-1} \cdot{ }^{34} \mathrm{~A}$ subsequent nucleophilic ring opening by imidate can furnish the vicinal diamine product 2 . Interestingly, an intermediate with a $\mathrm{C}_{1}-\mathrm{O}$ bond similar to IM1 was observed during the oxidation of 1,1-diphenyl ethylene using PIDA in the absence of HFIP. ${ }^{30}$

Earlier reports suggested that fluorinated solvents such as hexafluoroisopropanol (HFIP) are more beneficial in hypercoordinate iodine mediated reactions. ${ }^{35}$ For example, the improved reactivity of PIDA in the presence of HFIP is attributed to hydrogen bonding between the ligands on PIDA and HFIP ${ }^{36}$ which makes the ligands more labile. ${ }^{37}$ We have considered a similar scenario wherein the displaced imidate nitrogen is hydrogen bonded in $\mathbf{C 1}^{\prime}$ as shown in Fig. 2. Interestingly, the

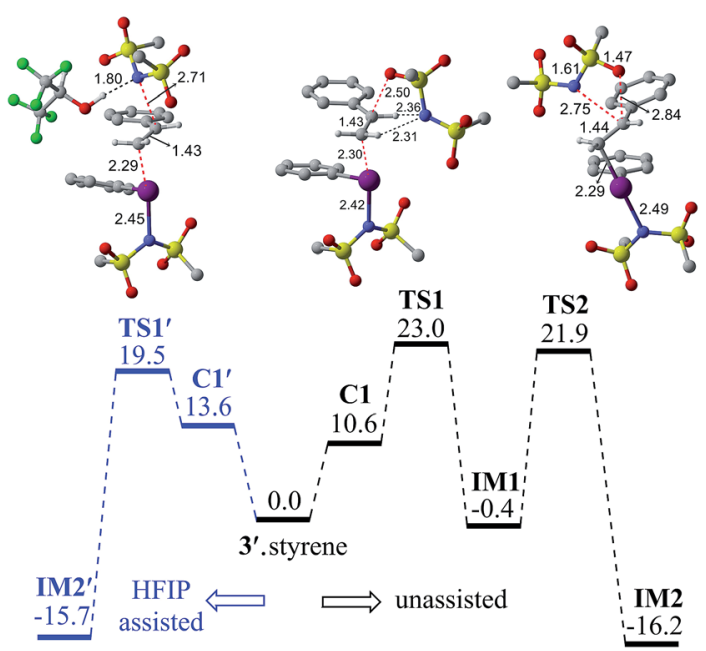

Fig. 1 Gibbs free energy (in $\mathrm{kcal} \mathrm{mol}^{-1}$ ) profile obtained at the $\mathrm{SMD}_{\text {(diethylether) }} / \mathrm{M06}-2 \mathrm{X} / 6-31 \mathrm{G} * *, \mathrm{SDD}$ (I) level of theory for the HFIP assisted (left, in blue color) and unassisted (right) iodonium ion formation. Optimized geometries of TS1', TS1 and TS2 are shown. All distances are in $\AA$. 


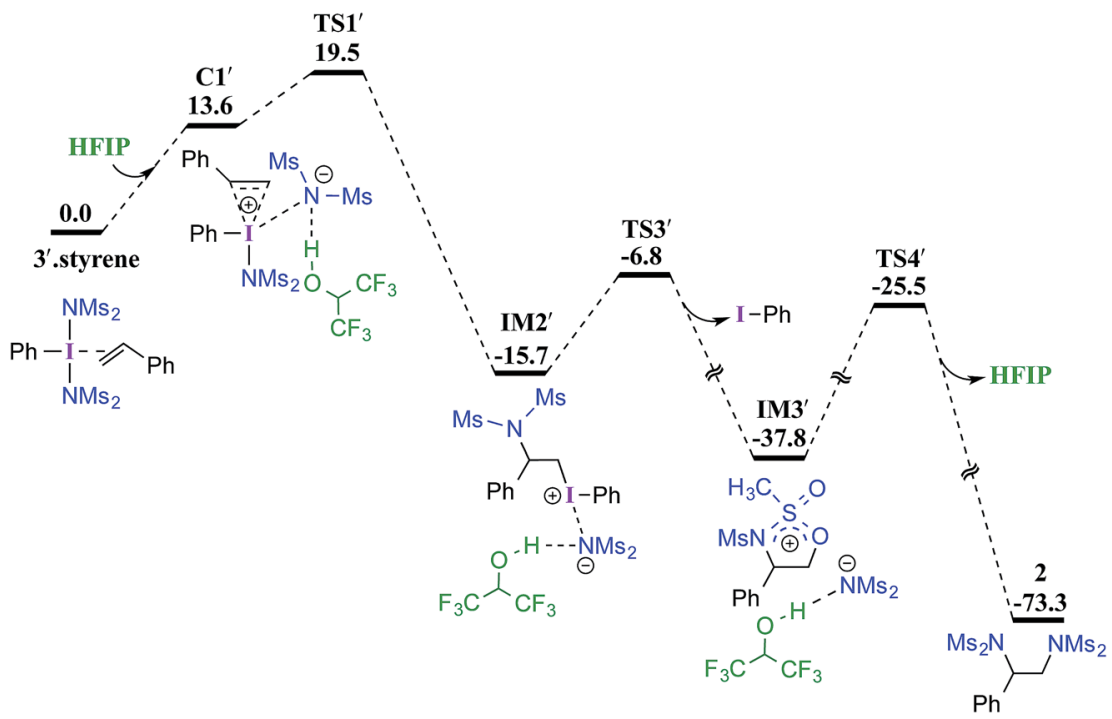

Fig. 2 Gibbs free energy (in kcal mol ${ }^{-1}$ ) profile calculated at the SMD (diethylether)/M06-2X/6-31G**,SDD(I) level of theory for the HFIP assisted diamination of styrene.

ensuing nucleophilic addition (TS1') on the styrenyl carbon is noted to occur through the imidate nitrogen. The natural charge on the HFIP-bound imidate nitrogen is higher $(-1.34)$ than that on the unbound $(-1.32)$. However, the nucleophilicity index of the HFIP-bound nitrogen is lower (0.58) than that of the unbound (0.61), indicating relatively softer nitrogen in the former case. Thus, explicit involvement of HFIP enables direct formation of the $\mathrm{N}-\mathrm{C}$ bond in $\mathbf{C} \mathbf{1}^{\prime}$ leading to $\mathbf{I M 2}{ }^{\prime}$. An alternative nucleophilic addition through the imidate oxygen is found to be $4.0 \mathrm{kcal} \mathrm{mol}^{-1}$ higher in energy when imidate is associated with HFIP. The HFIP-assisted nucleophilic addition exhibits a barrier of $19.5 \mathrm{kcal} \mathrm{mol}^{-1}$, which is $3.5 \mathrm{kcal} \mathrm{mol}^{-1}$ lower than that of the unassisted nucleophilic addition (Fig. 1). ${ }^{38}$ Having understood that the HFIP-assisted pathway is energetically preferable, we calculated the energetics for the HFIP-assisted formation of diamine product 2 as shown in Fig. $2 .^{39}$

After shedding light on the mechanism of vicinal diamination of styrene using $\mathrm{PhI}\left(\mathrm{NMs}_{2}\right)_{2}$, we have extended these insights to an asymmetric diamination catalyzed by $C_{2}$ symmetric iodoresorcinol based chiral catalysts to establish the factors controlling enantioselectivity. As described earlier, nucleophilic addition at the benzylic carbon (TS1') is more preferred than at the terminal carbon of the catalyst-substrate complex $\mathbf{C 1}^{\prime}$. The stereochemical outcome of the reaction will therefore be dictated by which of the prochiral faces of styrene binds to the iodine center. It is likely that the chiral environment offered by the catalyst could make the binding through one prochiral face energetically more preferred over the other in the ion-pair catalyst-substrate complex $\mathbf{C 1}^{\prime}$. In other words, the efficiency of this prochiral face recognition is expected to impact on the extent of enantioselectivity.

The process of stereoinduction is investigated by examining the stereoelectronic features of the in situ generated catalytically active hypercoordinate iodine species $\mathbf{4}^{\prime}$. In the most preferred conformer of the $C_{2}$-symmetric $\mathbf{4}^{\prime}$, the chiral arms fold in a right-handed $P$ helical fashion and generate a chiral environment around the iodine. The $(R)$-configured stereogenic center at the $\mathrm{C}_{\alpha}$ is the source of stereoinduction, which facilitates the fold with right-handed $P$ helicity. The corresponding $M$ helical fold is found to be of $8.0 \mathrm{kcal} \mathrm{mol}^{-1}$ higher energy. ${ }^{12,40} \mathrm{~A}$ series of weak non-covalent interactions (NCIs) between the imidate ligands and the chiral arms of the resorcinol backbone (Fig. 3) are found to arrange the chiral arms in a helical assembly. This folded assembly of the catalyst provides an asymmetric environment for the incoming styrene. How the binding of the $s i$ and re prochiral faces of styrene to the iodine is recognized differently in the catalyst-substrate complexes is analyzed using the cationic complexes $\left(\mathbf{C 1}^{+}\right)$devoid of the displaced nucleophile imidate associated with HFIP. ${ }^{41}$ It is noticed that the catalyst-substrate complex $\mathbf{C 1}_{s i}{ }^{+}$wherein styrene interacts through its $s i$ face is lower by $1.8 \mathrm{kcal} \mathrm{mol}^{-1}$ than the corresponding $r e$ face binding $\left(\mathbf{C 1}_{r e}{ }^{+}\right)$.

The differential recognition of the styrenyl prochiral faces can be understood as follows. In the $s i$ face catalyst-substrate complex, styrene is dispositioned closer to the iodine center, as evident from the shorter $\mathrm{C}_{2}-\mathrm{I}$ distance $(2.61 \AA)$ than in the $r e$ complex $(2.74 \AA)$, indicating enhanced catalyst-substrate interaction (Fig. 4). Further, the styrene double bond is noted to remain staggered and orthogonal with respect to the $\mathrm{C}_{4}-\mathrm{I}_{3}$ bond of the catalyst $\left(\theta_{(\mathrm{C} 1-\mathrm{C} 2-\mathrm{I} 3-\mathrm{C} 4)}=90.3^{\circ}\right)$ in $\mathbf{C 1}_{\text {si }}{ }^{+}$whereas it is eclipsed in $\mathbf{C 1}_{r e}{ }^{+}\left(\theta_{(\mathrm{C} 1-\mathrm{C} 2-\mathrm{I} 3-\mathrm{C} 4)}=8.8^{\circ}\right) .{ }^{42}$ The arrangement of styrene in these catalyst-substrate complexes facilitates a C$\mathrm{H} \cdots \pi$ interaction between the $\mathrm{C}_{\alpha}-\mathrm{H}$ of the chiral side chain and the phenyl group of styrene (shown as $a$ in Fig. 4). A larger deviation from the eclipsed alignment of the styrene double bond in the re complex (measured in terms of dihedral $\theta_{(\mathrm{C} 1-\mathrm{C} 2-}$ 13-C4) will result in loss of this critical interaction. Additional weak noncovalent interactions are noticed in the si mode of binding, which are absent in the re complex. Natural bond orbital (NBO) analysis revealed an enhanced $\pi$ electron 


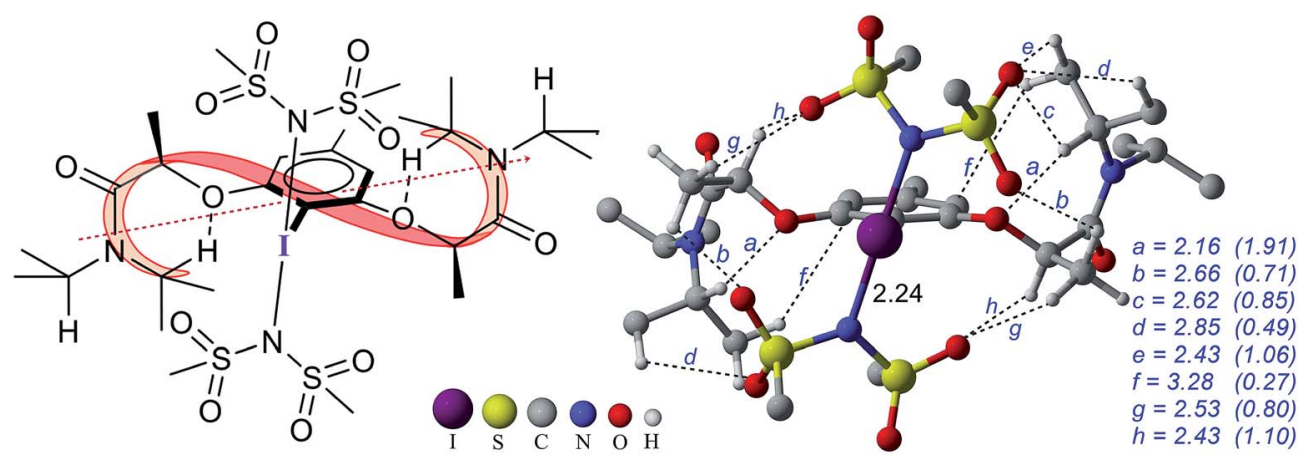

Fig. 3 Optimized geometry of catalytically active species $4^{\prime}$. All distances are in $\AA$ and relative energies are in $\mathrm{kcal}^{\mathrm{mol}}{ }^{-1}$. Important noncovalent interactions $(a-h)$ are shown in blue with the corresponding electron densities $\left(\rho \times 10^{-2}\right.$ au in parentheses) at the bond critical points along the bond paths. Only selected hydrogen atoms are shown for improved clarity. The helical axis (red dotted line) formed due to the folding of the chiral side chain (ribbon-like depiction) is shown in the structure on the left.

delocalization from the styrene double bond to the I-N antibonding orbital in $\mathbf{C 1}_{s i}{ }^{+}\left(46.1 \mathrm{kcal} \mathrm{mol}^{-1}\right)$ compared to that in $\mathbf{C 1}_{r e}{ }^{+}\left(30.7 \mathrm{kcal} \mathrm{mol}^{-1}\right)$. Comparison of a free styrene with a bound styrene as noted in the catalyst-substrate complexes is carried out to understand the effect of iodine coordination on the reactivity and selectivity.

To examine how the relative orientation of the styrene double bond and the Ar-I bond influences their energies, catalystsubstrate complexes with staggered and eclipsed orientations of the substrate are analyzed for an achiral catalyst (Fig. 5a). The staggered arrangement $\left(\mathbf{C}_{\text {sta }}{ }^{+}\right)$is found to be $1.0 \mathrm{kcal} \mathrm{mol}^{-1}$ lower in energy than the eclipsed geometry $\left(\mathbf{C 1}_{\text {ecl }}{ }^{+}\right)$. In the case of the achiral catalyst, binding of both the prochiral faces of styrene is found to be energetically similar, suggesting no facial discrimination.

To gather more insights, the $\pi$ and $\pi^{*}$ natural bond orbitals (NBOs) in a free styrene as well as those in an iodine-bound styrene are analyzed. These are critical NBOs, as the donor $\pi$ and acceptor $\pi^{*}$ are, respectively, involved in the catalystsubstrate complex formation and in the nucleophilic addition. Both benzylic $\left(\mathrm{C}_{1}\right)$ and terminal carbon $\left(\mathrm{C}_{2}\right)$ atoms of the free styrene contribute equally to the $\pi$ orbital as evident from the corresponding orbital coefficients $\left(\mathrm{C}_{1}=\mathrm{C}_{2}=0.70\right.$, Fig. $\left.5 \mathrm{~b}\right)$. Interestingly, in the catalyst-substrate complexes, the $\pi$ orbital is polarized toward the terminal carbon as indicated by a higher orbital coefficient on $\mathrm{C}_{2}$ than that on $\mathrm{C}_{1}$ whereas the corresponding $\pi^{*}$ orbital is more polarized toward the benzylic<smiles>CC1OC(Oc2ccccc2OC2C(C)N(S(C)(=O)=O)C(C)C(=O)N2C(C)C)C(C)N(C(C)C)C1=O</smiles>

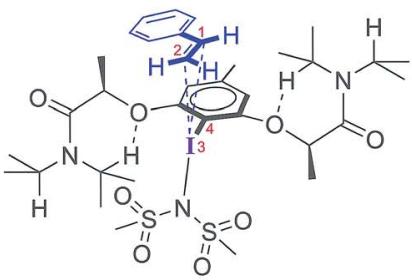
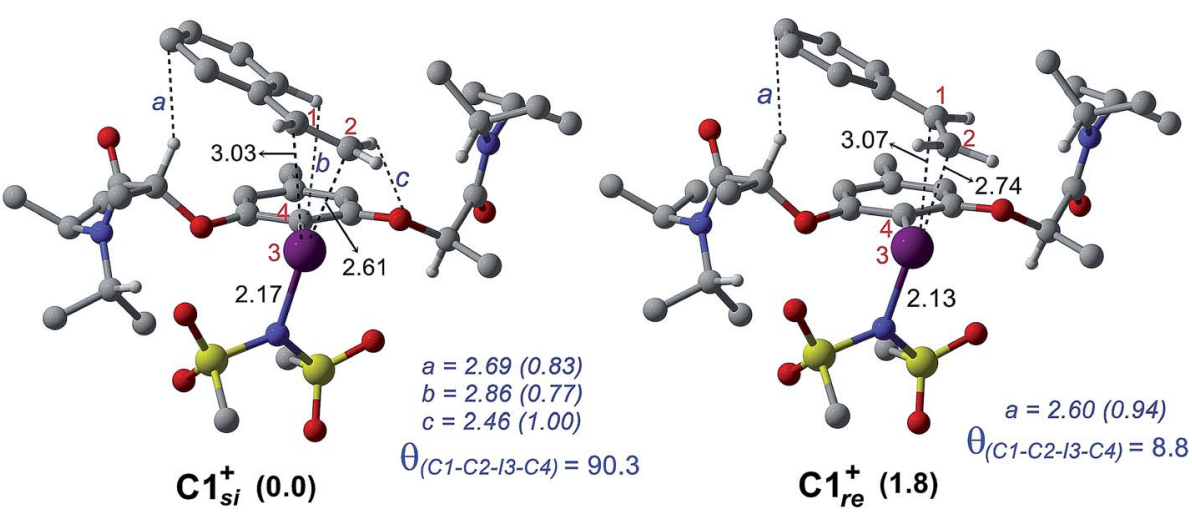

Fig. 4 Optimized geometries of cationic catalyst-substrate complexes $\mathrm{C}_{s i}{ }^{+}$and $\mathrm{C1}_{r e}{ }^{+}$as well as the corresponding qualitative representations. All distances are in $\AA$ and relative energies are in $\mathrm{kcal} \mathrm{mol}^{-1}$. Important noncovalent interactions $(a-c)$ are shown in blue with the corresponding electron densities $\left(\rho \times 10^{-2}\right.$ au in parentheses) at the bond critical points along the bond paths. Only selected hydrogen atoms are shown for improved clarity. 
a)

b)
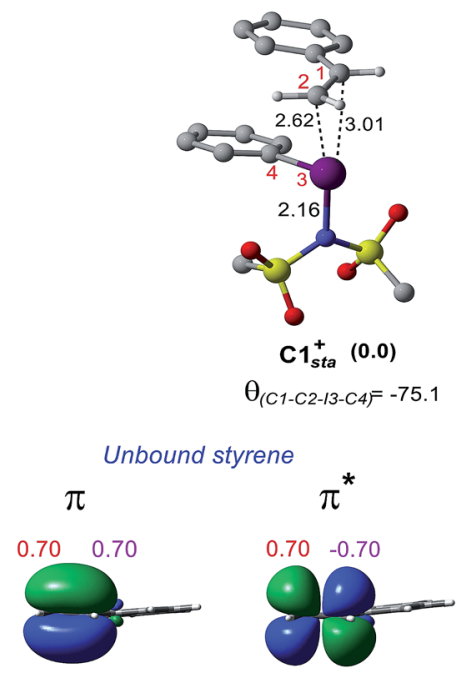

Achiral Catalyst Bound Complex
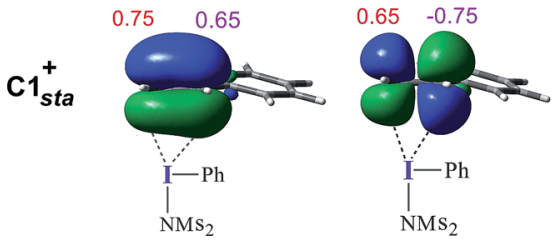

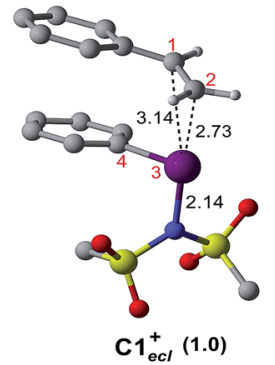

c)

$\theta_{(C 1-C 2-13-C 4)}=-31.2$
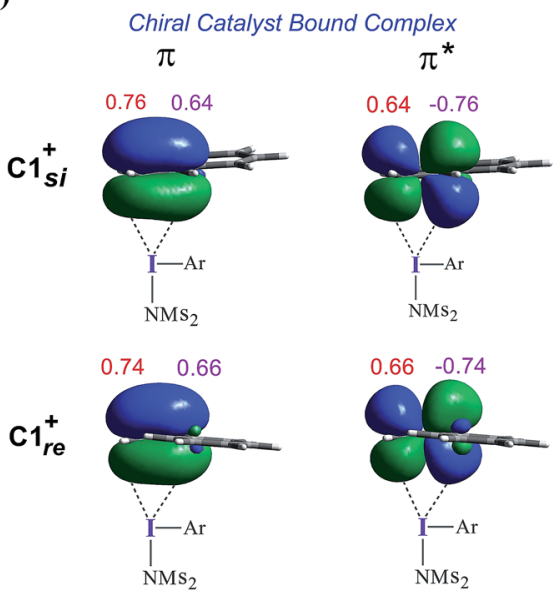

Fig. 5 (a) Optimized geometries of $\mathrm{C}_{\text {sta }}{ }^{+}$and $\mathrm{C}_{\text {ecl }}{ }^{+}$. (b) Important natural bond orbitals (NBOs) corresponding to the $\pi$ and $\pi^{*}$ of (b) a free styrene as well as those in the iodine achiral catalyst-substrate complex $\mathrm{C1}_{\text {sta }}{ }^{+}$, and (c) in the chiral catalyst-substrate complexes. Orbital coefficients on $C_{1}$ (in purple) and $C_{2}$ (in red) carbon atoms are given for each NBO.

carbon $\mathrm{C}_{1}$. In the achiral catalyst-substrate complexes, the $\pi$ orbital polarization is noted to be higher in the case of the staggered geometry of styrene in $\mathbf{C}_{1}{ }_{\text {sta }}{ }^{+}$(coefficients on $\mathrm{C}_{1}$ and $\mathrm{C}_{2}$ are 0.65 and 0.75 , respectively) compared to that in $\mathrm{C1}_{\text {ecl }}{ }^{+}\left(\mathrm{C}_{1}\right.$ $=0.64$ and $\left.\mathrm{C}_{2}=0.76\right) \cdot{ }^{43}$ More interestingly, a differential polarization of the $\pi$ and $\pi^{*}$ is noted in the chiral catalystsubstrate complexes depending on the prochiral face through which styrene binds to the iodine center. The styrene double bond in the si binding mode, which has a staggered arrangement, is found to be more polarized than in the re complex (Fig. 5c). The orbital coefficients for filled $\pi$ in $\mathbf{C 1}_{\text {si }}{ }^{+}$are $\mathrm{C}_{1}=$ 0.64 and $\mathrm{C}_{2}=0.76$ and those in $\mathbf{C 1}_{r e}{ }^{+}$are $\mathrm{C}_{1}=0.66$ and $\mathrm{C}_{2}=$ 0.74 . The chirality induced differential polarization of the styrenyl double bond, as described here, can have a pronounced impact on the prochiral face recognition and hence the stereochemical course of the reaction. Akin to the orbital polarization noted here, the natural charge on $\mathrm{C}_{1}$ and $\mathrm{C}_{2}$ exhibited similar features..$^{43}$ In summary, the enhanced polarization of the styrene $\pi$ orbitals, particularly that of the $\pi^{*}$ orbital in the lower energy staggered catalyst-substrate complex, improves the propensity toward the nucleophilic addition of the imidate ion.

In the next step, stereoselective addition of the imidate on the benzylic position of styrene bound to chiral catalyst $\mathbf{4}^{\prime}$ is considered (for the geometry of the catalyst, see Fig. 3). The C-N bond formation via TS1 ${ }^{\prime}$ leads to the formation of an iodonium ion intermediate $\left(\mathbf{I M 2}^{\prime}\right)$. Nucleophilic addition of the imidate to the catalyst-substrate complexes $\mathbf{C 1}^{\prime}{ }_{\boldsymbol{s} i}$ and $\mathbf{C} \mathbf{1}^{\prime}{ }_{\boldsymbol{r}}$ is separately examined ${ }^{44}$ The transition state for the imidate addition to the open $r e$ face of the bound styrene in $\mathbf{C 1}^{\prime}{ }_{\boldsymbol{s i}}$ is denoted as $\mathbf{T S}^{\prime}{ }_{\boldsymbol{S}}$ as the new stereogenic center created in this mode would be of $S$ configuration. The relative Gibbs energy of $\mathbf{T S 1}^{\prime}{ }_{S}$ is found to be $6.5 \mathrm{kcal} \mathrm{mol}^{-1}$ lower in energy than that of $\mathbf{T S}^{\prime}{ }_{\boldsymbol{R}}$. Similarly, the elementary step barrier for the nucleophilic addition through $\mathbf{T S 1}^{\prime}{ }_{\boldsymbol{S}}$ is $3.1 \mathrm{kcal} \mathrm{mol}^{-1}$ lower than that for $\mathbf{T S 1}^{\prime}{ }_{\boldsymbol{R}}$. A staggered arrangement of the styrene double bond $\left(\theta_{(\mathrm{C} 1-\mathrm{C} 2-\mathrm{I} 3-\mathrm{C} 4)}=89.2^{\circ}\right)$ with respect to the Ar-I bond is noted in the lower energy TS1 ${ }^{\prime}$ s whereas it remains in an eclipsed $\left(\theta_{(\mathrm{C} 1-\mathrm{C} 2-\mathrm{I} 3-\mathrm{C} 4)}=21.4^{\circ}\right)$ geometry in the higher energy TS1 $^{\prime}{ }_{\boldsymbol{R}^{*}}{ }^{45}$ Analysis of TSs shows the presence of certain types of noncovalent interactions (denoted as $h$ and $i$ in Fig. 6) between the reactants (styrene and imidate) and the catalyst in the case of $\mathbf{T S 1}^{\prime}{ }_{\boldsymbol{S}}$ which are absent in $\mathbf{T S}^{\prime}{ }_{\boldsymbol{R}}$. However, these weakly differentiating interactions are rather inadequate toward rationalizing an overwhelming preference for imidate addition via $\mathbf{T S 1}^{\prime}{ }_{\boldsymbol{s}}$. Hence, we have performed activation-strain analysis on these diastereomeric TSs by fragmenting them into three parts such as the catalyst, styrene and nucleophile. All three fragments in $\mathbf{T S}^{\prime}{ }_{\boldsymbol{R}}$ exhibited relatively higher distortion energy than in $\mathbf{T S 1}^{\prime}{ }_{\boldsymbol{s}}$ - the sum of which amounts to $14.4 \mathrm{kcal} \mathrm{mol}^{-1}$ in the former. ${ }^{46}$ The stabilizing interaction energy between these three fragments is also higher $\left(-6.9 \mathrm{kcal} \mathrm{mol}^{-1}\right)$ in $\mathbf{T S 1}^{\prime}{ }_{\boldsymbol{R}}$. On balance, the distortion appears 


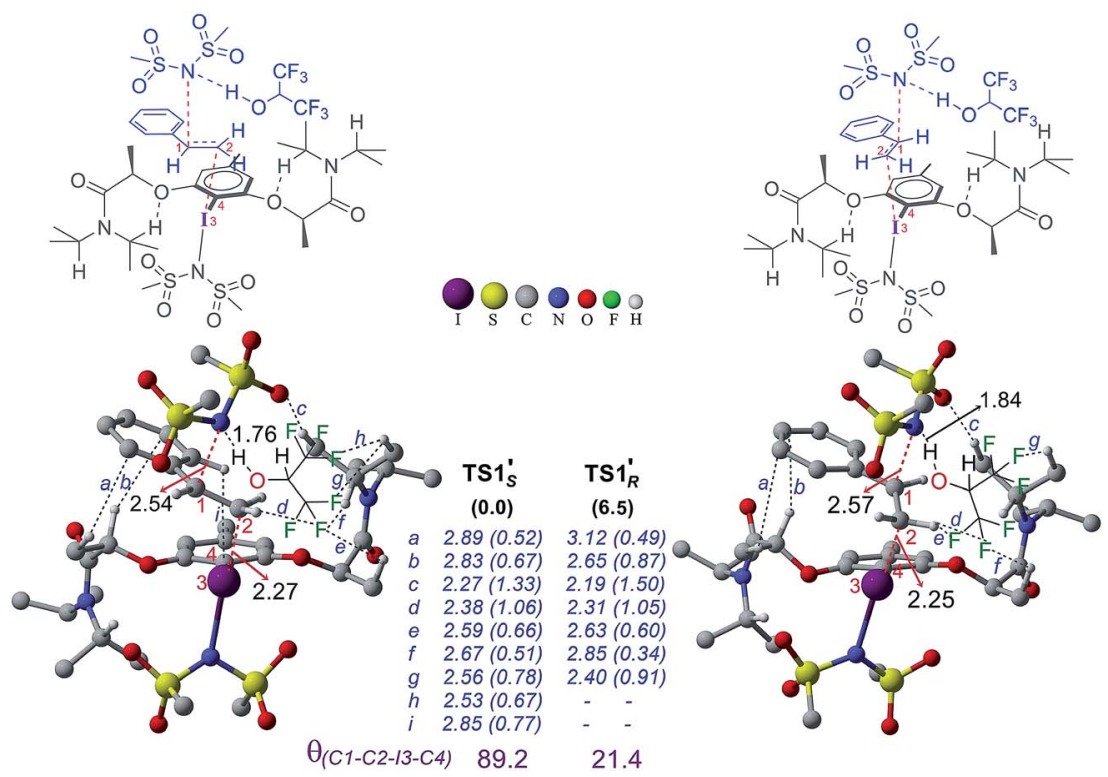

Fig. 6 Optimized geometries of the stereoselective transition states $\mathrm{TS}^{\prime}{ }_{S}$ and $\mathrm{TS}_{1}^{\prime}{ }_{R}$. Relative Gibbs free energy is given in parentheses. Important noncovalent interactions $(a-i)$ are shown in blue along with the corresponding electron densities $\left(\rho \times 10^{-2}\right.$ au in parentheses) at the bond critical points along the bond paths. All distances are in $\AA$.

to be a key contributor of the energy difference between the diastereomeric TSs. The difference in the elementary step barriers for the nucleophilic addition of the imidate on the re face of the catalyst-substrate complex and that on the $s i$ face is found to be $3.1 \mathrm{kcal} \mathrm{mol}^{-1}$, exhibiting a preference toward the formation of the $S$ enantiomeric product. ${ }^{47}$ While the difference in barriers corresponds to an ee of $98 \%$ which is in good agreement with the experimental observation of $94 \%$, the relative energies of the diastereomeric transition states result in a modest overestimation of ee.

\section{Conclusions}

The energetically favorable mechanism and the origin of enantioselectivity in hypercoordinate iodine catalyzed vicinal diamination of styrene have been identified. Styrene coordination to the electrophilic iodine center polarizes the double bond making the benzylic carbon susceptible to nucleophilic addition by imidate derived from the active catalyst $\operatorname{ArI}\left(\mathrm{NMs}_{2}\right)_{2}$. Hexafluoroisopropanol-assisted nucleophilic addition for the $\mathrm{C}-\mathrm{N}$ bond formation proceeds with a lower energy barrier and results in an iodonium ion intermediate. Under the chiral environment provided by the iodoresorcinol catalyst, the coordination of the si prochiral face of styrene is more preferred due to the relatively more effective catalystsubstrate interaction than in the re face complex. This prochiral face recognition is found to have a direct impact on the enantioselectivity of this catalytic asymmetric reaction. The kinetic advantage for nucleophilic addition of the imidate is more for the si-face of the catalyst-substrate complex, which could be traced to a relatively lower distortion in the reactant partners in the stereocontrolling transition state. The computed \% ee is in good agreement with the experimental observation.

\section{Conflicts of interest}

The authors declare no competing financial interest.

\section{Acknowledgements}

Generous computing time from SpaceTime supercomputing at IIT Bombay and the Ohio (OSC) Supercomputer Center is gratefully acknowledged. C. M. H. gratefully acknowledges financial support from the U.S. National Science Foundation (CHE-1566106).

\section{Notes and references}

1 (a) D. Lucet, T. Le Gall and C. Mioskowski, Angew. Chem., Int. Ed., 1998, 37, 2580-2627; (b) S. De Jong, D. G. Nosal and D. J. Wardrop, Tetrahedron, 2012, 68, 4067-4105.

2 (a) N. Fu, G. S. Sauer, A. Saha, A. Loo and S. Lin, Science, 2017, 357, 575-579; (b) J. B. Parry, N. Fu and S. Lin, Synlett, 2018, 29, 257-265.

3 (a) F. Cardona and A. Goti, Nat. Chem., 2009, 1, 269; (b) Y. Zhu, R. G. Cornwall, H. Du, B. Zhao and Y. Shi, Acc. Chem. Res., 2014, 47, 3665-3678; (c) K. Muñiz and C. Martínez, J. Org. Chem., 2013, 78, 2168-2174.

4 R. M. Romero, T. H. Wöste and K. Muñiz, Chem.-Asian J., 2014, 9, 972-983.

5 (a) A. Yoshimura and V. V. Zhdankin, Chem. Rev., 2016, 116, 3328-3435; (b) Y. Li, D. P. Hari, M. V. Vita and J. Waser, Angew. Chem., Int. Ed., 2016, 55, 4436-4454; (c) X. Wang and A. Studer, Acc. Chem. Res., 2017, 50, 1712-1724; (d) 
L. Wang and J. Liu, Eur. J. Org. Chem., 2016, 2016, 1813-1824; (e) A. Sreenithya, K. Surya and R. B. Sunoj, Wiley Interdiscip. Rev.: Comput. Mol. Sci., 2017, 7, e1299.

6 C. Röben, J. A. Souto, Y. González, A. Lishchynskyi and K. Muñiz, Angew. Chem., Int. Ed., 2011, 50, 9478-9482.

7 (a) J. A. Souto, Y. González, A. Iglesias, D. Zian, A. Lishchynskyi and K. Muñiz, Chem.-Asian J., 2012, 7, 1103-1111; (b) A. Lishchynskyi and K. Muñiz, Chem.-Eur. J., 2012, 18, 2212-2216; (c) R. M. Romero, J. A. Souto and K. Muñiz, J. Org. Chem., 2016, 81, 6118-6122.

8 K. Muñiz, L. Barreiro, R. M. Romero and C. Martínez, J. Am. Chem. Soc., 2017, 139, 4354-4357.

9 (a) S. Haubenreisser, T. H. Wöste, C. Martínez, K. Ishihara and K. Muñiz, Angew. Chem., Int. Ed., 2016, 55, 413-417; (b) E. M. Woerly, S. M. Banik and E. N. Jacobsen, J. Am. Chem. Soc., 2016, 138, 13858-13861; (c) S. M. Banik, J. W. Medley and E. N. Jacobsen, Science, 2016, 353, 51-54; (d) H. Chen, A. Kaga and S. Chiba, Org. Biomol. Chem., 2016, 14, 54815485; (e) T. Kitamura, A. Miyake, K. Muta and J. Oyamada, J. Org. Chem., 2017, 82, 11721-11726; $(f)$ W. Kong, P. Feige, T. de Haro and C. Nevado, Angew. Chem., Int. Ed., 2013, 52, 2469-2473; (g) U. Farid and T. Wirth, Angew. Chem., Int. Ed., 2012, 51, 3462-3465; (h) I. G. Molnár and R. Gilmour, J. Am. Chem. Soc., 2016, 138, 5004-5007; (i) T. H. Wöste and K. Muñiz, Synthesis, 2016, 48, 816-827.

10 (a) M. Fujita, Tetrahedron Lett., 2017, 58, 4409-4419; (b) M. Uyanik and K. Ishihara, J. Synth. Org. Chem., Jpn., 2012, 70, 1116-1122.

11 A. Flores, E. Cots, J. Bergès and K. Muñiz, Adv. Synth. Catal., 2019, 361, 2-25.

12 A. Sreenithya, C. Patel and R. B. Sunoj, ACS Catal., 2017, 7, 4189-4196.

13 M. J. Frisch, G. W. Trucks, H. B. Schlegel, G. E. Scuseria, M. A. Robb, J. R. Cheeseman, G. Scalmani, V. Barone, B. Mennucci, G. A. Petersson, H. Nakatsuji, M. Caricato, X. Li, H. P. Hratchian, A. F. Izmaylov, J. Bloino, G. Zheng, J. L. Sonnenberg, M. Hada, M. Ehara, K. Toyota, R. Fukuda, J. Hasegawa, M. Ishida, T. Nakajima, Y. Honda, O. Kitao, H. Nakai, T. Vreven, J. A. Montgomery Jr, J. E. Peralta, F. Ogliaro, M. Bearpark, J. J. Heyd, E. Brothers, K. N. Kudin, V. N. Staroverov, R. Kobayashi, J. Normand, K. Raghavachari, A. Rendell, J. C. Burant, S. S. Iyengar, J. Tomasi, M. Cossi, N. Rega, N. J. Millam, M. Klene, J. E. Knox, J. B. Cross, V. Bakken, C. Adamo, J. Jaramillo, R. Gomperts, R. E. Stratmann, O. Yazyev, A. J. Austin, R. Cammi, C. Pomelli, J. W. Ochterski, R. L. Martin, K. Morokuma, V. G. Zakrzewski, G. A. Voth, P. Salvador, J. J. Dannenberg, S. Dapprich, A. D. Daniels, O. Farkas, J. B. Foresman, J. V. Ortiz, J. Cioslowski and D. J. Fox, Gaussian 09, Revision D.01, Gaussian, Inc., Wallingford CT, 2013.

14 Y. Zhao and D. G. Truhlar, Theor. Chem. Acc., 2008, 120, 215241.

15 (a) P. C. Hariharan and J. A. Pople, Theor. Chim. Acta, 1973, 28, 213-222; (b) V. Rassolov, J. A. Pople, M. Ratner and T. L. Windus, J. Chem. Phys., 1998, 109, 1223-1229.
16 (a) D. Andrae, U. Haussermann, M. Dolg, H. Stoll and H. Preuss, Theor. Chim. Acta, 1990, 77, 123-141; (b) P. Fuentealba, H. Stoll, L. von Szentpály, P. Schwerdtfeger and H. Preuss, J. Phys. B: At. Mol. Phys., 1983, 16, L323-L328. 17 A. V. Marenich, C. J. Cramer and D. G. Truhlar, J. Phys. Chem. B, 2009, 113, 6378-6396.

18 (a) K. Fukui, Acc. Chem. Res., 1981, 14, 363-368; (b) C. Gonzalez and H. B. Schlegel, J. Chem. Phys., 1989, 90, 2154-2161; (c) C. Gonzalez and H. B. Schlegel, J. Phys. Chem., 1990, 94, 5523-5527.

19 (a) R. Pluta, P. E. Krach, L. Cavallo, L. Falivene and M. Rueping, ACS Catal., 2018, 8, 2582-2588; (b) R. Frei, M. D. Wodrich, D. P. Hari, P.-A. Borin, C. Chauvier and J. Waser, J. Am. Chem. Soc., 2014, 136, 16563-16573; (c) S. Beaulieu and C. Y. Legault, Chem.-Eur. J., 2015, 21, 11206-11211; (d) C. Zhu, Y. Liang, X. Hong, H. Sun, W.-Y. Sun, K. N. Houk and Z. Shi, J. Am. Chem. Soc., 2015, 137, 7564-7567; (e) M. Li, X.-S. Xue, J. Guo, Y. Wang and J.-P. Cheng, J. Org. Chem., 2016, 81, 3119-3126; (f) H. Jiang, T.-Y. Sun, X. Wang, Y. Xie, X. Zhang, Y.-D. Wu and H. F. Schaefer, Org. Lett., 2017, 19, 6502-6505; $(g)$ B. Zhou, M. K. Haj, E. N. Jacobsen, K. N. Houk and X. Xue, J. Am. Chem. Soc., 2018, 140, 15206-15218; (h) J. Zhao and S. Li, J. Org. Chem., 2017, 82, 2984-2991.

20 (a) R. F. W. Bader, Atoms in Molecules: A Quantum Theory, Clarendon Press, Oxford, 1990; (b) AIM2000, Version 2.0, The Buro fur Innovative Software, SBK-Software, Bielefeld, Germany, 2000.

21 E. D. Glendening, J. K. Badenhoop, A. E. Reed, J. E. Carpenter, J. A. Bohmann, C. M. Morales, C. R. Landis and F. Weinhold, NBO 6.0., Theoretical Chemistry Institute, University of Wisconsin, Madison, 2013.

22 (a) F. M. Bickelhaupt, J. Comput. Chem., 1999, 20, 114-128; (b) W. J. van Zeist and F. M. Bickelhaupt, Org. Biomol. Chem., 2010, 8, 3118-3127; (c) F. M. Bickelhaupt and K. N. Houk, Angew. Chem., Int. Ed., 2017, 56, 10070-10086.

23 R. F. Ribeiro, A. V. Marenich, C. J. Cramer and D. G. Truhlar, J. Phys. Chem. B, 2011, 115, 14556-14562.

24 (a) P. Y. Ayala and H. B. Schlegel, J. Chem. Phys., 1998, 108, 2314-2325; (b) S. Grimme, Chem.-Eur. J., 2012, 18, 99559964; (c) See Table S1 in the ESI $\dagger$ for further details.

25 See Table S5 in the ESI $\dagger$ for further details.

26 In the stoichiometric reaction using PIDA (3) and $\mathrm{HNMs}_{2}$, the in situ generated diaminating species was identified as $\mathrm{PhI}\left(\mathrm{NMs}_{2}\right)_{2} \quad\left(3^{\prime}\right)$ by using IR spectroscopic and X-ray crystallographic studies. Formation of $3^{\prime}$ from 3 can occur through an exoergic ligand exchange where iodine-bound acetate of PIDA abstracts a proton from $\mathrm{HNMs}_{2}$ to form a molecule of acetic acid. See Scheme S1 in the $\mathrm{ESI} \dagger$ for additional details. The anionic imidate ligands $\left(\mathrm{NMs}_{2}{ }^{-}\right)$on active species $\mathbf{3}^{\prime}$ are known to be labile in solution and exist in equilibrium with the cationic iodine species $\left(\mathrm{PhINMs}_{2}{ }^{+}\right)$. See J. A. Souto, C. Martínez, I. Velilla and K. Muñiz, Angew. Chem., Int. Ed., 2013, 52, 1324-1328.

27 In stoichiometric reactions, undesirable co-production of Ar-I is generally reported while it is oxidized back to 
catalytically active hypercoordinate iodine species $[\mathbf{I}]^{\prime}$ in the catalytic variant of these reactions.

28 H. Pinto de Magalhães, A. Togni and H. P. Lüthi, J. Org. Chem., 2017, 82, 11799-11805.

29 See Fig. S1 in the ESI. $\dagger$

30 Similar situations have been noticed earlier in I. FunesArdoiz, W. M. C. Sameera, R. M. Romero, C. Martínez, J. A. Souto, D. Sampedro, K. Muñiz and F. Maseras, Chem.Eur. J., 2016, 22, 7545-7553. See Fig. S4 in the ESI† for the charge distribution in the imidate ligand.

31 The Gibbs free energy of the $\mathrm{C}-\mathrm{O}$ bond formation transition state at $\mathrm{C}_{2}$ is found to be $8.0 \mathrm{kcal} \mathrm{mol}^{-1}$ higher than at the $\mathrm{C}_{1}$ position.

32 (a) The Fukui index for nucleophilicity at a specific site is calculated as $f_{\mathrm{A}}^{-}=P_{\mathrm{A}}(N)-P_{\mathrm{A}}(N-1)$, where $P_{\mathrm{A}}$ is the electron population in atom $\mathrm{A}$ and $N$ is the number of electrons of the molecule; $(b)$ R. G. Parr and W. Yang, $J$. Am. Chem. Soc., 1984, 106, 4049-4050.

33 For IM1, an alternative intramolecular nucleophilic addition of the imidate nitrogen on the $\mathrm{C}_{1}$ is found to involve a higher barrier. See Fig. S3 in the ESI $\dagger$ for further details.

34 See Fig. S2 in the ESI $\dagger$ for the Gibbs free energy profile.

35 (a) T. Dohi, N. Yamaoka and Y. Kita, Tetrahedron, 2010, 66, 5775-5785; (b) I. Colomer, R. Coura Barcelos and T. J. Donohoe, Angew. Chem., Int. Ed., 2016, 55, 4748-4752; (c) M. Ito, C. Ogawa, N. Yamaoka, H. Fujioka, T. Dohi and Y. Kita, Molecules, 2010, 15, 1918-1931; (d) M. Uyanik, T. Yasui and K. Ishihara, Angew. Chem., Int. Ed., 2013, 52, 9215-9218; (e) K. Morimoto, K. Sakamoto, T. Ohshika, T. Dohi and Y. Kita, Angew. Chem., Int. Ed., 2016, 55, 36523656; (f) K. Murai, T. Kobayashi, M. Miyoshi and H. Fujioka, Org. Lett., 2018, 20, 2333-2337; $(g)$ J. Iskra and S. S. Murphree, Tetrahedron Lett., 2017, 58, 645-648; (h) T. Dohi, M. Ito, K. Morimoto, Y. Minamitsuji, N. Takenaga and Y. Kita, Chem. Commun., 2007, 4152-4154; (i) I. Colomer, A. E. R. Chamberlain, M. B. Haughey and T. J. Donohoe, Nat. Rev. Chem., 2017, 1, 0088; (j) H. K. Minhas, W. Riley, A. M. Stuart and M. Urbonaite, Org. Biomol. Chem., 2018, 16, 7170-7173.

36 I. Colomer, C. Batchelor-McAuley, B. Odell, T. J. Donohoe and R. G. Compton, J. Am. Chem. Soc., 2016, 138, 8855-8861.
37 S. Izquierdo, S. Essafi, I. del Rosal, P. Vidossich, R. Pleixats, A. Vallribera, G. Ujaque, A. Lledós and A. Shafir, J. Am. Chem. Soc., 2016, 138, 12747-12750.

38 Additional calculations at the B3LYP-D3/6-31G**,SDD(I) and energy refinements at the B3LYP-D3/6-311+G**,SDD(I) were done to learn that consistently similar trends exist across different basis sets and density functionals. See Table S5 in the $\mathrm{ESI} \dagger$ for details.

39 Alternative possibilities such as an aziridinium pathway which involves an intramolecular nucleophilic addition of the imidate nitrogen on $\mathrm{C}_{2}$ and a direct $\mathrm{S}_{\mathrm{N}} 2$ pathway are also investigated for the conversion of IM2' to product 2 . Further details are provided in Scheme S2 and Fig. S5 in the ESI. $\dagger$

40 See Fig. S8 and S9 in the ESI $\dagger$ for details on other conformers of $\mathbf{4}^{\prime}$.

41 The energy difference between the cationic catalystsubstrate complexes primarily originates due to the difference in the prochiral face through which the substrate interacts with the chiral catalyst. In a neutral catalyst-substrate complex, the achiral nucleophile imidate (bound to HFIP), which exists as a counterion, interacts with the rest of the system through a set of weak noncovalent interactions. Hence, the energy of the neutral catalyst-substrate complexes is dependent on the positioning of the counterion.

42 M. Hickey, D. Goeddel, Z. Crane and Y. Shi, Proc. Natl. Acad. Sci. U. S. A., 2004, 101, 5794-5798.

43 See Table S6 in the ESI $\uparrow$ for more details.

44 The neutral catalyst-substrate complex $\mathbf{C 1}^{\prime}{ }_{\boldsymbol{s i}}$ is $3.4 \mathrm{kcal} \mathrm{mol}{ }^{-1}$ lower in energy than $\mathbf{C 1}^{\prime}{ }$ e .

45 Similar geometric disposition of alkenes with respect to the Ar-I bond was recently noted in a hypercoordinate iodine catalyzed difluorination reaction (see ref. $19 g$ ).

46 The distortion energies of the catalyst, styrene and HFIP bound imidate fragments in $\mathbf{T S 1}_{\boldsymbol{R}}{ }_{\boldsymbol{R}}$ are, respectively, 5.2, 3.9 , and $5.3 \mathrm{kcal} \mathrm{mol}^{-1}$ higher than the corresponding values in $\mathbf{T S 1}_{\boldsymbol{s}}{ }_{\boldsymbol{s}}$. See Table S7 in the ESI† for more details.

47 The stereoselectivity model established for asymmetric diamination of styrene can as well be extended to internal alkenes. See Fig. S12 and Scheme S3 in the ESI $\dagger$ for further details. 